\title{
Influence of Logical/Mathematical Intelligence Intervention to Foster Active Learning Among the Elementary School Children
}

\author{
Ms. Amitha $\mathbf{V}^{1}$, Dr. A. H. M. Vijayalaxmi ${ }^{2}$ \\ ${ }^{1}$ Research Scholar, ${ }^{2}$ Associate Professor \\ Department of Human Development and Research Centre, \\ Smt. V.H.D. Central Institute of Home Science, Bangalore, Karnataka, India
}

\section{ABSTRACT}

Multiple Intelligences theory put forth by Howard Gardner (1983) is an innate faculty present in every individual in a unique combination. It is just not one form of intellect but eight different abilities, i.e., linguistic, logical, musical, kinesthetic, spatial, intrapersonal, interpersonal and naturalistic. The purpose of the present study was to find out the Influence of logical intelligence to foster active learning among the elementary school children. A self-structured Multiple Intelligences Inventory with 0.729 Cronbach's alpha and 0.638 split-half correlation and Active Learning scale with 0.896 Cronbach's alpha and 0.85 split-half correlation was administered to the respondents. The sample consists of 100 respondents of both gender studying in sixth standard, with 50 children for experimental group of Ramanashree Udaya Education Society and 50 for control group of Seshadripuram School. The students were initially assessed using Multiple Intelligences Inventory and grouped based on their intelligences. A group which was dominant with logical/mathematical intelligence was considered for the study. Social Science curriculum which the subject teacher expressed as a perceived difficult subject among the students was identified for intervention program. Hence the educational modules were developed in accordance with logical/mathematical intelligence for social science curriculum. The results of the investigation revealed a significant difference between the pre-test and post-test scores of active learning, indicating that logical/mathematical intelligence intervention had an influence on active learning among the children of experimental group. Whereas among the control group respondents the differences between the pre and post test scores was found to be non- significant. Hence identifying the dominant intelligence in the children and helping them to recognize their own potentials while imparting curriculum as well encouraging them to learn accordingly is very crucial.

KEY TORDS: Multiple Intelligences, Logical/Mathematical, Dominant, Active Learning

\section{INTRODUCTION}

Education, especially at primary level is given paramount importance in Indian educational system as it the foundation for fruitful future. Primary education does not only mean a classroom, books and a teacher but creating an environment where a child can learn new things every day and help in bringing out best within a child. The literature reveals that students often struggle to learn in a traditional classroom where rote learning is given more importance.

Learning will be successful when the child enjoys it. To make learning enjoyable and interesting, teachers should tailor the curriculum according to the child's intelligence profile. Therefore, Multiple Intelligences Theory, a brainchild of Dr. Howard Gardner (1983) has opened the doors to many children. There are eight intelligences - Verbal/Linguistic Intelligence, Logical/Mathematical Intelligence, Musical/Rhythmic Intelligence, Bodily/Kinesthetic Intelligence, Visual/Spatial Intelligence, Intrapersonal Intelligence, Interpersonal Intelligence and Naturalistic Intelligence.

Children at this age have the ability to think conceptually and abstractly and capacity to discern logical or numerical patterns. Hence the teacher should encourage the children's thinking ability through the curriculum in a classroom. 
According to the Reena (2000), "Recognizing Logical Intelligence enhances the optimum growth and development of intellectual skills of children". The teachers can facilitate teaching learning through the use of brain teasers, problem solving, experiments, mental calculation, number games, critical thinking, cause/effect relationship in their teaching as well as while giving them their assignments. (Madhumita, 2016).

Teaching logical learners requires logical and numerical pattern-oriented lesson planning. When curriculum is imparted in this method children are benefited as follows:

$>$ Allowing the learners to be recognized and rewarded for their strengths;

$>$ Provides opportunities for learners to adapt their studies to their interests and learning preferences;

$>$ Reduces the chances of boredom by offering a variety of activities; and

$>$ Provides a teaching/learning methodology that works.

Hence, this study has made an attempt to impart social science curriculum with Logical/Mathematical Intelligence activities and to find out its effect on active learning among elementary school children.

\section{METHODOLOGY}

Aim: To find out the Influence of Logical/Mathematical Intelligence Intervention to foster Active Learning for the Social Science curriculum among the Elementary School Children

\section{Objectives:}

$>$ To profile the logical intelligence and active learning of elementary school children.

$>$ To develop educational modules on social science curriculum using logical intelligence activities.

$>$ To administer the developed modules to the experimental group.

$>$ To find out the differential influence of intervention program on active learning.

$>$ To find out the difference between the active learning scores among control group and experimental group.

\section{Hypotheses:}

1. There was no significant difference between the pre and post-test mean scores of the following aspects of active learning among experimental group respondents

a. Do b. Review

c. Learn

d. Apply

2. There was no significant difference between the mean scores of experimental and control group respondents on the aspects of active learning considered for the study.

\section{Research Design}

Phase I- Identification/development of appropriate tools

An extensive survey was carried out to identify the most appropriate tools. The investigator has done a thorough review of literature and a market survey of availability of Multiple Intelligences scale and Active Learning scale. As researcher was not able to get the suitable scales for the present study, both Multiple Intelligences and Active Learning scales were developed. The internal consistency for Multiple Intelligences Inventory was 0.729 and for Active Learning scale 0.827 for Cronbach's alpha. The reliability for Multiple Intelligences Inventory was 0.638 and Active Learning scale 0.921 for split-half correlation, indicating high reliability of the scales.

\section{Phase II - Identification of schools}

A survey of both Private and Government elementary schools in Bangalore city was carried out to identify the schools for the research program. The researcher wanted two schools - one for experimental and another for control group. The management of the schools which showed keen interest and readily gave the permission to conduct the intervention program during the class hours was considered for the experimental group. Another school which was situated far away from the experimental school and willing to take participation in the research was selected as a control group to avoid the spill-over effect of the intervention program. Thus, Ramanashree Udaya Education Society was selected for the experimental study and Seshadripuram School was taken as the control group study.

\section{Phase III: Selection of sample}

From the Elementary schools identified in the previous phase, 50 children studying in sixth grade from Ramanashree Udaya Education Society were randomly selected for the experimental group and similarly 50 children studying in sixth grade from Seshadripuram School, was identified as a control group. 
PHASE IV: Pre-test Assessment

Initially a pre-test was conducted on the selected group for the study to understand the type of Multiple Intelligences prevailing and levels of Active Learning of sixth grade children by administrating both Multiple Intelligences Inventory and Active Learning scales. After MI pre-assessment it was observed that children had logical intelligence as dominant intelligence.

\section{PHASE V: Teaching-Learning Materials (TLMs)} Development

For the development the Teaching-Learning Materials (TLMs) the researcher wanted to focus on one subject. After deliberation with the class teachers it was found that Social Science subject was perceived as a difficult subject by the students and hence the academic scores were also low for this subject as compare to other subjects. Hence researcher identified Social Science subject for intervention and the Teaching-Learning Materials (TLMs) were designed and developed based on the identified dominant intelligence, i.e., logical/mathematical intelligence for the elementary school children.

\section{PHASE VI: Implementation of the Intervention Program}

The developed Teaching-Learning Materials (TLMs) were utilized to impart Social Science subject to the experimental group during the subject class hours daily for a duration of one semester. Each aspect of the Social Science curriculum was covered using the logical intelligence educational activities to foster the active learning among the respondents.

\section{PHASE VII: Post Assessment}

Active Learning scale was re-administered to find out the influence of intervention program on Active Learning scores of the respondents.

\section{PHASE VIII: Analysis and interpretation of data}

Analysis of the data was done using Mean, Standard Deviation, Chi Square and Student ' $t$ ' test. Interpretation of data and conclusions are presented in the results and discussion.

\section{RESULTS AND DISCUSSION}

TABLE - 1: Classification of Respondents by Socio-Demographic Variables

\begin{tabular}{|c|c|c|c|c|c|c|c|c|}
\hline \multirow{3}{*}{ Characteristics } & \multirow{3}{*}{ Category } & \multicolumn{6}{|c|}{ Respondents } & \multirow{3}{*}{$\begin{array}{c}\chi^{2} \\
\text { Test }\end{array}$} \\
\hline & & \multicolumn{2}{|c|}{ Control } & \multicolumn{2}{|c|}{ Experimental } & \multicolumn{2}{|c|}{ Combined } & \\
\hline & & $\mathbf{N}$ & $\%$ & $\mathbf{N}$ & $\%$ & $\mathbf{N}$ & $\%$ & \\
\hline \multirow{2}{*}{ Age group (years) } & $\quad 10-11 S S$ & 22 & 44.0 & 23 & 46.0 & 45 & 45.0 & \multirow{2}{*}{$0.04^{\mathrm{NS}}$} \\
\hline & $12-13$ & 28 & 56.0 & 27 & 54.0 & 55 & 55.0 & \\
\hline Total & 10, & 50 & 100.0 & 50 & 100.0 & 100 & 100.0 & \\
\hline \multirow{2}{*}{ Gender } & Boys & 30 & 60.0 & 25 & 50.0 & 55 & 55.0 & \multirow{2}{*}{$1.01^{\mathrm{NS}}$} \\
\hline & Girls & 20 & 40.0 & 25 & 50.0 & 45 & 45.0 & \\
\hline Total & & 50 & 100.0 & 50 & 100.0 & 100 & 100.0 & \\
\hline \multirow{3}{*}{ Ordinal position } & First born & 26 & 52.0 & 22 & 44.0 & 48 & 48.0 & \multirow{3}{*}{$1.18^{\mathrm{NS}}$} \\
\hline & Second born & 20 & 40.0 & 21 & 42.0 & 41 & 41.0 & \\
\hline & Later born & 4 & 8.0 & 7 & 14.0 & 11 & 11.0 & \\
\hline Total & & 50 & 100.0 & 50 & 100.0 & 100 & 100.0 & \\
\hline \multirow{4}{*}{ Number of siblings } & No & 3 & 6.0 & 6 & 12.0 & 9 & 9.0 & \multirow{4}{*}{$12.76 *$} \\
\hline & One & 21 & 42.0 & 35 & 70.0 & 56 & 56.0 & \\
\hline & Two & 17 & 34.0 & 6 & 12.0 & 23 & 23.0 & \\
\hline & More than Three & 9 & 18.0 & 3 & 6.0 & 12 & 12.0 & \\
\hline Total & & 50 & 100.0 & 50 & 100.0 & 100 & 100.0 & \\
\hline
\end{tabular}

The Table 1 depicts the experimental and control group respondents' demographic data. The analysis of each of these variables are presented below. 
Age:

Majority of both experimental group (54\%) and control group respondents $(56 \%)$ were belong to the age group of 12-13 years. Hence, there was no significant difference found between the experimental and control group respondents with respect to age distribution.

\section{Gender:}

Majority (60\%) of control group respondents were boys, whereas, among experimental group, there was an equal distribution ( $50 \%$ each) of the respondents between both the genders. However, there was no statistical significant difference found between the groups.

\section{Ordinal Position:}

When the ordinal position was considered, majority of both experimental (44\%) and control group (52\%) respondents were first born. The next highest percentage of both experimental $(42 \%)$ and control group respondents $(40 \%)$ were second born. A small percentage of the respondents' of both control and experimental group fall under later born category $(8 \%$ and $14 \%$ respectively). Hence, 1.18 score was the statistical difference found between the groups which is statistically non-significant.

\section{Number of Siblings:}

The elucidated information on number of siblings clearly indicates that majority of experimental group (70\%) respondents and considerable percentage of the control group respondents $(42 \%)$ had only one sibling. Considerable percentage $34 \%$ of the respondents were in control group while equal percentage (12\% each) of experimental group respondents were belong to both second and no siblings' categories. A small percentage of control group respondents $(6 \%)$ had no siblings. The analysis indicates differences between experimental and control group respondents with respect to number of siblings' variable. Hence, the statistical analysis indicates 12.76 significant differences at $5 \%$ level.

Table 2: Assessment of Logical/Mathematical Intelligence among the respondents

\begin{tabular}{|c|c|c|c|c|c|}
\hline \multirow{2}{*}{ Aspect of Intelligence } & \multicolumn{2}{|c|}{ Experimental Group } & \multicolumn{2}{|c|}{ Control Group } & \multirow{2}{*}{ 't' 'Test } \\
\hline & Mean & SD & Mean & SD & \\
\hline Logical/Mathematical Intelligence & 7.36 & 1.59 & 7.60 & 2.07 & $0.6502^{\mathrm{NS}}$ \\
\hline
\end{tabular}

NS: Non-significant

The Table 2 represents the mean scores of logical intelligence among experimental group and control group respondents. The mean logical intelligence score for the experimental group was 7.36 while for the control group respondents 7.60. However, when the above data was subjected to statistical analysis, non-significant difference was observed between the groups.

Table - 3: Pre and post assessment of Active learning among Experimental group

\begin{tabular}{|c|c|c|c|c|}
\hline \multirow{2}{*}{ Aspect } & \multirow{2}{*}{ Response } & \multicolumn{2}{|c}{ Scores } & Paired \\
\cline { 3 - 4 } & & Mean & SD & 't' Test \\
\hline \multirow{2}{*}{ Do } & Pre & 14.82 & 2.06 & \multirow{2}{*}{$23.31 *$} \\
\cline { 2 - 4 } & Post & 22.94 & 2.35 & \\
\hline \multirow{2}{*}{ Review } & Pre & 4.74 & 1.77 & \multirow{2}{*}{$14.37 *$} \\
\cline { 2 - 4 } & Post & 8.98 & 1.30 & \\
\hline \multirow{2}{*}{ Learn } & Pre & 7.52 & 2.19 & \multirow{2}{*}{$17.59 *$} \\
\cline { 2 - 4 } & Post & 13.92 & 1.58 & \\
\hline \multirow{2}{*}{ Apply } & Pre & 3.88 & 1.67 & \multirow{2}{*}{$17.28 *$} \\
\cline { 2 - 4 } & Post & 8.96 & 1.38 & \\
\hline \multicolumn{3}{|c|}{$*$ Significant at 5\% level } \\
\hline
\end{tabular}

Figure 1

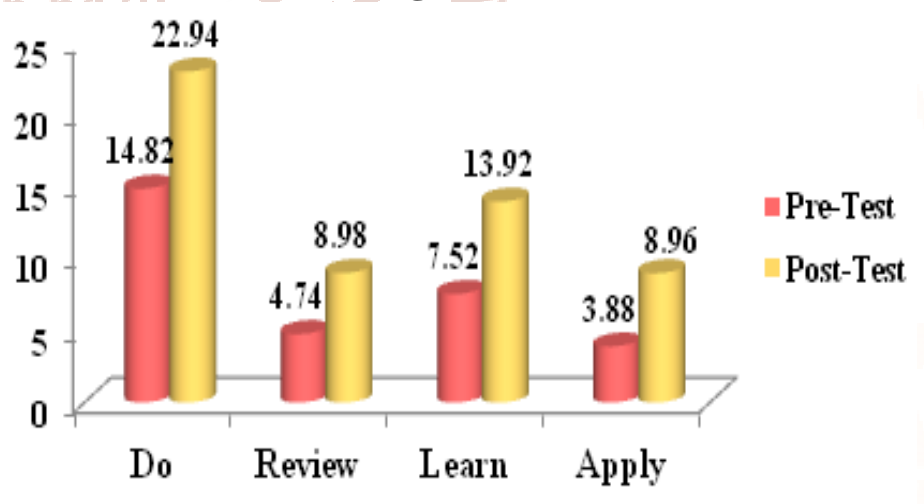

A social science curriculum based on logical intelligence intervention was given to the respondents to nurture the active learning. Logical intelligence based intervention Teaching-Learning Materials designed and developed with activities like logical reasoning, number coding, problem-solving, number games, etc. were given to teach social science curriculum to enhance active learning among the experimental group respondents. 
The Table 3 and Figure 1 depicts the pre and post assessment of active learning among the experimental group respondents. When the above data was subjected to statistical analysis, it indicated a significant difference between the pre and post-test active learning mean scores for all the aspects of active learning, as follows: Do (Pre-test 14.82 to Posttest 22.94); Review (Pre-test 4.74 to Post-test 8.98); Learn (Pre-test 7.52 to Post-test 13.92); and Apply (Pre-test 3.88 to Post-test 8.96) with post-test scores showing higher than the pre-test scores. Hence when the above data was subjected to find out the statistical significant differences between pre and post-test mean scores for all the aspects of active learning, a strongly significant difference was observed at 5\% level indicating intervention was very effective in nurturing active learning skills among the respondents.

Hence, the hypothesis (1) stating that there was no significant difference between the pre and post-test scores of experimental group respondents on all the aspects of active learning considered for the study was rejected.

Table - 4: Pre and post Assessment of Active learning among Control group

\begin{tabular}{|c|c|c|c|c|}
\hline \multirow{2}{*}{ Aspect } & \multirow{2}{*}{ Response } & \multicolumn{2}{|c|}{ Scores } & \multirow{2}{*}{ Paired } \\
\cline { 2 - 4 } & & Mean & SD & ' $t$ ' Test \\
\hline \multirow{2}{*}{ Do } & Pre & 11.16 & 2.02 & \multirow{2}{*}{$4.31^{*}$} \\
\cline { 2 - 4 } & Post & 10.62 & 2.12 & \\
\hline \multirow{2}{*}{ Review } & Pre & 4.18 & 1.27 & \multirow{2}{*}{$1.76^{\text {NS }}$} \\
\cline { 2 - 4 } & Post & 4.24 & 1.25 & \\
\hline \multirow{2}{*}{ Learn } & Pre & 6.36 & 1.66 & \multirow{2}{*}{$1.42^{\text {NS }}$} \\
\cline { 2 - 4 } & Post & 6.4 & 1.16 & \\
\hline \multirow{2}{*}{ Apply } & Pre & 4.5 & 1.37 & \multirow{2}{*}{$0.77^{\text {NS }}$} \\
\cline { 2 - 4 } & Post & 4.56 & 1.32 & \multicolumn{2}{|c|}{} \\
\hline
\end{tabular}

* Significant at 5\% level, NS: Non- Significant

Control group respondents did not receive any intervention to impart social science curriculum. These respondents were taught the social science curriculum with regular teaching methods in the school by their teachers.

The Table 4 represents the pre and post-test scores of active learning among the control group respondents. When the above data was subjected to statistical analysis, no significant differences was observed between the pre and post-test active learning mean scores for all the aspects of active learning except for one, the Do aspect for which the mean scores in the post test was low 10.62 compared to pre-test scores (11.16).

Table - 5: Post Assessment Comparison of Active Learning among Experimental and Control group respondents

\begin{tabular}{|c|c|c|c|c|c|}
\hline \multirow{2}{*}{ Aspect } & \multicolumn{2}{|c|}{ Experimental } & \multicolumn{2}{c|}{ Control } & Paired \\
\cline { 2 - 6 } & Mean & SD & Mean & SD & ' Test \\
\hline Do & 22.94 & 2.35 & 10.62 & 2.12 & $28.22^{*}$ \\
\hline Review & 8.98 & 1.30 & 4.24 & 1.25 & $17.70^{*}$ \\
\hline Learn & 13.92 & 1.58 & 6.4 & 1.61 & $22.89^{*}$ \\
\hline Apply & 8.96 & 1.38 & 4.56 & 1.32 & $15.32^{*}$ \\
\hline Total & 54.8 & 5.02 & 26.2 & 6.63 & $27.81^{*}$ \\
\hline
\end{tabular}

Figure 2

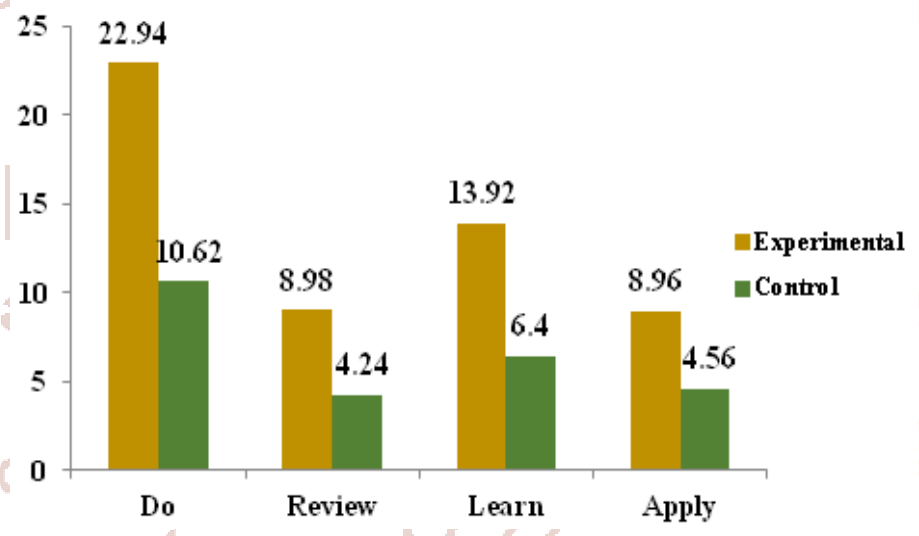

The Table 5 and Figure 2 exemplifies the post assessment scores of active learning among the experimental and control group respondents. The respondents of the experimental group were introduced to the intervention program while the control group respondents were not. When the above data was subjected to statistical analysis, a significant difference was observed between the experimental and control group respondents on all the aspects of active learning mean scores. The mean scores of experimental group respondents were higher than the mean scores obtained by the control group respondents. Thus, when the above data subjected to find the statistical significant differences between experimental and control group respondents' a significant difference at $5 \%$ level was noted for all the aspects of Active Learning.

Hence, the hypothesis (2) stating that there was no significant difference of the mean scores of active learning between the experimental group and control group children on all the aspects of active learning considered for the study was rejected. 


\section{CONCLUSION}

The present study shows the Logical Intelligence intervention for social science curriculum was found to have a significant effect on the Active Learning among the elementary school children. Children tend to be more innovative and explorative during this stage of life, hence the logical intelligence educational activities have opened new doors to explore their learning atmosphere and encourage their thought process.

Identifying the dominant intelligence in the children and helping them to recognize their own potentials and incorporate these activities in teaching learning of social sciences will enhance their academics.

\section{REFERENCES}

1. Dr. Madhumita (2016), "Innovative Teaching of Social Sciences to Enhance Multiple
Intelligence”. IOSR Journal Of Humanities And Social Science (IOSR - JHSS) Volume 21 , Issue 2, PP 54 - 60. E-ISSN: 2279-0837, p-ISSN: 22790845 .

2. Gardner H (1983), "Frames of mind: the theory of Multiple Intelligences". New York, NY: Basic Books.

3. Gardner H (1999), "Intelligence reframed: Multiple Intelligences for the 21st century". New York, NY: Basic Books.

4. Reena S. D. (2000), "Intervention programme for young children on Multiple Intelligence". Unpublished dissertation, Chaudhary Charan Singh Haryana Agricultural University, Hisar.

5. Solomon Ortiz. "Education Quotes". https://www.brainyquote.com/topics/education 